UCRL-ID-126405

\title{
Coupled Models in Low-Frequency Electromagnetic Simulation
}

\section{LDRD Final Report 94-ERI-004}

\author{
Principal Investigator: \\ Dennis W. Hewett \\ Co-Investigators: \\ Bill Bateson, Matthew Gibbons, Michael Lambert, Louann Tung, and Garry Rodrigue \\ Lawrence Livermore National Laboratory
}

February 3, 1997

This is an informal report intended primarily for internal or limited extemal distribution. The opinions and conclusions stated are those of the author and may or may not be those of the Laboratory.

Work performed under the auspices of the U.S. Department of Energy by the Lawrence Livermore National Leboratory under Contract W-7405-ENG-48. 


\section{DISCLAIMER}

This document was prepared as an account of work sponsored by an agency of the United States Government. Neither the United States Government nor the University of California nor any of their employees, makes any warranty, express or implied, or assumes any legal liability or responsibility for the accuracy, completeness, or usefulness of any information, apparatus, product, or process disclosed, or represents that its use would not infringe privately owned rights. Reference herein to any specific commercial product, process, or service by trade name, trademark, manufacturer, or otherwise, does not necessarily constitute or imply its endorsement, recommendation, or favoring by the United States Government or the University of California. The views and opinions of authors expressed herein do not necessarily state or reflect those of the United States Government or the University of California, and shall not be used for advertising or product endorsement purposes.

This report has been reproduced directly from the best available copy.

Available to DOE and DOE contractors from the Office of Scientific and Technical Information

P.O. Box 62, Oak Ridge, TN 37831

Prices available from (615) 576-8401, FTS 626-8401

Available to the public from the

National Technical Information Service

U.S. Department of Commerce

5285 Port Royal Rd.,

Springfield, VA 22161 
Final Report

(LDRD Exploratory Research in the Institutes, 94-ERI-004)

\title{
Coupled Models in Low-Frequency Electromagnetic Simulations UCRL - ID - 126405
}

\author{
Principal Investigator: Dennis W. Hewett
}

Co-Investigators: Bill Bateson, Matthew Gibbons, Michael Lambert, Louann Tung, Garry Rodrigue

With the support from this LDRD, we have produced innovative computational methods for low-frequency EM simulation through coupling of existing and new techniques. These algorithms have a broad range of applications, well beyond our initial focus on plasma-aided manufacturing. We chose plasma processing as our primary application because of the potentially strong industrial interest and the associated LLNL experimental program that produced measurements useful for bench marking our codes. It is obvious that codes produced for this application have usefulness in many other areas besides plasma processing. These applications, magnetic fusion, accelerators magnetic bearings, magnetic storage read/write head performance, etc., received growing fractions of our attention in the later stages of this work

We developed a range of new capabilities in the course of this funding. Responding to a need to include realistic chemistry and ionization in the driven plasmas in plasma-aided manufacture, we became convinced that existing computational tools were not able to fulfill our requirements. In response to this, we invented an entirely new approach to such problems. Our approach is to generalize the capabilities of existing methods: ParticleIn-Cell (PIC) contains the required details of the distributions but becomes overwhelming expensive when applied to realistic, multidimensional problems. The common alternative, the hydrodynamic model, has simply lost the ability to model this science because of the simple fluid assumption. Our solution [1], GaPH (for Grid and Particle Hydrodynamics), retains the kinetic capabilities of PIC while using fluid concepts within each particle to control the incredible expense. The coupling of these two methods has resulted in a very powerful new algorithm that is now being applied to a range of programmatic problems thoughout LLNL that now far outstrips the initial applications area. 
Similarly, our work in low-frequency EM models, while generally adequate to handle the initial plasma processing applications, became inadequate as we began to see the capabilities and possibilities of the powerful new kinetic transport algorithms. To this end, we have revamped some of our most useful algorithms, ZMR (a zero-electron inertia EM model)[2,3], and a combination of AVANTI (an implicit PIC/EM model)[4,3] and SDF (a Streamlined Darwin Field model) [4,5,6]. These new models DADIPIC (for DArwin Direct Implicit PIC plus SDF) [7,8] and BLITZ [9](a far more capable ZMR) have led to a world of new applications (fast-ignitor modeling for ICF, magnetic read/write heads, etc.) that amply demonstrates the flexibility and breadth of competency that can be obtained by mixing the capability of these models.

We have also added to our computational infrastructure in two important ways: 1) we have invented a new way to spread a banded linear system across multiple processors [10] which has led to a new massively parallel solution capability [11] and 2) have found a way to include or Embedded Curved Boundaries [12] into an orthogonal mesh. Both these capabilities are essential to realize the power that the coupling of existing and new plasma models have made possible. 


\section{REFERENCES}

1. W.B. Bateson and D.W. Hewett, "Grid and Particle Hydrodynamics: Beyond Hydrodynamics via Fluid Element Particle-In-Cell", UCRL-JC-125049, J. Comp. Phys., (submitted 7/25/96).

2. D.W. Hewett, "Global Method of Solving the Electron-Field Equations in a ZeroInertia-Electron-Hybrid Plasma Simulation Code", J. Comp. Phys., 38, 378 (1980).

3. D.W. Hewett, "Low-frequency Electromagnetic (Darwin) applications in plasma simulation", UCRL-JC-117152, Rev. 1, Comp Phys. Comm., 84, pg. 243-277, 1994.

4. D.W. Hewett and A. B. Langdon, "Electromagnetic Direct Implicit Plasma Simulation", UCRL-JC-126409, J. Comp. Phys., 72, pg. 121, 1987.

5. D.W. Hewett, D.J. Larson and S.J. Doss, " Solution of Simultaneous Partial Differential Equations Using Dynamic ADI: Solution of the Streamlined Darwin Field Equations", UCRL-JC-105039, Rev. 1, J. Comp. Phys., 101, pg. 11, 1992.

6. G.J.DiPeso D.W. Hewett and G.F. Simonson, "Extension of the Streamlined Darwin Model to Quisineutral Plasmas", UCRL-JC-111281, J. Comp. Phys., 111, pg. 237, 1994.

7. M.R. Gibbons and D.W. Hewett, "The DArwin Direct Implicit Particle-in-Cell (DADIPIC)-Method for Simulation of Low Frequency Plasma Phenomena", UCRL-JC-118303, J. Comp. Phys., Sept. 1995, Aug.-94, Vol. 120, pg. 231-247.

8. M.R. Gibbons and D.W. Hewett, "Characterization of the DArwin Direct Implicit Particle-In-Cell (DADIPIC) Method and Resulting Guidelines for Operation", UCRL-JC-119199, J. Comp. Phys., Jan. 1997, Apr. .1996, Vol. 130, pg. 54-66.

9. N. Mattor, T.J. Williams, D.W. Hewett, "Algorithm for solving tridiagonal matrix problems in parallel", UCRL-JC-114756, Parallel Computing, 21, pg. 1769, 1995.

10. M.A. Lambert, "Field Simulation of Axisymmetric Plasma Screw Pinches By Alternating-Direction-Implicit Methods", UCRL-LR-125050, Ph.D. Thesis, UC Davis, Jun. 1996.

11. M.A. Lambert, "Parallel DADI Methods for Solution of the Steady State Diffusion Equation", UCRL-JC-123874, Journal of Parallel Computing, (submitted Apr.1996).

12. D.W. Hewett, "The Embedded Curved Boundary Method for Orthogonal Simulation Meshes", UCRL-JC-125649, Rev. 1, J. Comp. Phys., (submitted 12/4/96).

13. G. DiPeso, V. Vahedi, D.W. Hewett, and T. D. Rognlien, "Two-dimensional selfconsistent fluid simulation of radio frequency inductive sources", UCRL-JC-115684, J. Vac. Sci. Technol., A 12(4), Jul./Aug. 1994, pg. 1387-1396

14. G. DiPeso, T.D. Rognlien, V.Vahedi, and D.W. Hewett, "Equilibrium Profiles for RFPlasma Sources with Ponderomotive Forces", UCRL-JC-118342, IEEE Transactions on Plasma Science, Vol. 23, NO. 4, August 1995.

15. V. Vahedi, M.A. Liberman, G. DiPeso, T.D. Rognlien, and D.W. Hewett, "Analytic Model of Power Deposition in Inductively Coupled Plasma Sources", UCRL-JC-118723, J. Appl. Phys., July 9, 1994 


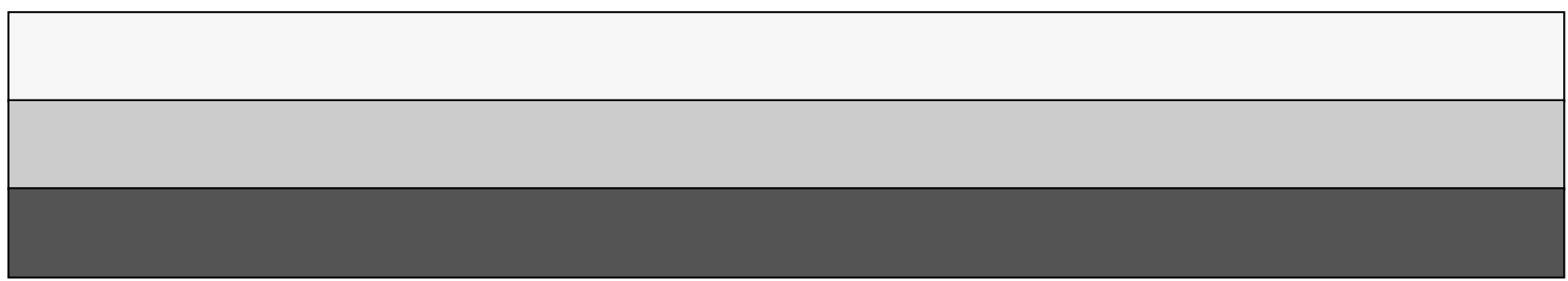

